\title{
p28, A first in class peptide inhibitor of cop1 binding to p53
}

\author{
T Yamada ${ }^{1}$, K Christov ${ }^{1}$, A Shilkaitis ${ }^{1}$, L Bratescu ${ }^{1}$, A Green ${ }^{1}$, S Santini ${ }^{2}$, A R Bizzarri ${ }^{2}$, S Cannistraro ${ }^{2}$, \\ T K D Gupta ${ }^{1}$ and C W Beattie ${ }^{\star, 1}$ \\ ${ }^{1}$ Department of Surgery, Division of Surgical Oncology, University of Illinois at Chicago College of Medicine, Chicago, IL, USA and \\ ${ }^{2}$ Biophysics and Nanoscience Centre, CNISM, Facoltà di Scienze, Università della Tuscia, Viterbo, Italy
}

Background: A 28 amino-acid (aa) cell-penetrating peptide (p28) derived from azurin, a redox protein secreted from the opportunistic pathogen Pseudomonas aeruginosa, produces a post-translational increase in p53 in cancer cells by inhibiting its ubiquitination.

\begin{abstract}
Methods: In silico computational simulations were used to predict motifs within the p53 DNA-binding domain (DBD) as potential sites for p28 binding. In vitro direct and competitive pull-down studies as well as western blot and RT-PCR analyses were used to validate predictions.
\end{abstract}

Results: The L1 loop (aa 112-124), a region within the S7-S8 loop (aa 214-236) and T140, P142, Q144, W146, R282 and L289 of the p53DBD were identified as potential sites for p28 binding. p28 decreased the level of the E3 ligase COP1 $>80 \%$, in p53 $3^{\text {wt }}$ and p5 $3^{\text {mut }}$ cells with no decrease in COP1 in p53dom/neg or p53null cells. Brief increases in the expression of the E3 ligases, TOPORS, Pirh2 and HDM2 (human double minute 2) in p53 ${ }^{\mathrm{wt}}$ and $\mathrm{p} 53^{\text {mut }}$ cells were in response to sustained increases in p53.

Conclusion: These data identify the specific motifs within the DBD of p53 that bind p28 and suggest that p28 inhibition of COP1 binding results in the sustained, post-translational increase in p53 levels and subsequent inhibition of cancer cell growth independent of an HDM2 pathway.

The cupredoxin azurin preferentially enters a wide variety of cancer cells, inducing p53-mediated cytostatic and cytotoxic (apoptotic) effects in murine and human cancer cells (Yamada et al, 2002; Punj et al, 2004; Apiyo and Wittung-Stafshede, 2005; Bizzarri and Cannistraro, 2009). Molecular modeling and atomic force microscopy studies suggest that azurin binds to the flexible $\mathrm{L}_{1}$ and $\mathrm{S}_{7}-\mathrm{S}_{8}$ loops of the p53 DNA-binding domain (DBD), forming a stable complex through tight protein-protein interactions (De Grandis et al, 2007; Taranta et al, 2008). Amino acids (aa) 50-67 (p18) and $50-77$ (p28) of azurin represent the protein transport domain (Yamada et al, 2005; Taylor et al, 2009) and motif (Yamada et al, 2009) responsible for azurin's antiproliferative activity, respectively. Exposure of p53 ${ }^{\mathrm{wt}} \mathrm{MCF}-7$ breast cancer cells to p28 induces a post-translational increase in the level and activity of p53, inhibits the cell cycle at the $\mathrm{G}_{2}-\mathrm{M}$ transition and induces apoptosis, but not in the isogenic $\mathrm{p} 53^{\mathrm{dom} / \mathrm{neg}}$ cell line MDD2 (Shaulian et al, 1992; Yamada et al, 2009).
Intracellular levels of p53 are tightly regulated by a series of ubiquitin E3 ligases that promote ubiquitination and proteasomal degradation of p53 (Michael and Oren, 2003). The most prominent is HDM2 (human double minute 2) (Haupt et al, 1997). Current small-molecule HDM2 antagonists MI-219/AT-219, RITA, PXN727, Nutlins (cis-imidazoline analogues) and JNJ-26854165 (Cheok et al, 2011) bind to HDM2 and inhibit the subsequent ubiquitination and proteolysis of wild-type p53. Unlike these agents, p28 forms a complex (Bizzarri et al, 2011) within aa 80-276 of the p53DBD that decreases ubiquitination (Yamada et al, 2009) and proteasomal degradation of p53 via an HDM2-independent pathway (Yamada et al, 2009). In addition to HDM2, other E3 ligases, COP1 (constitutively photomorphogenic 1), Pirh2 (p53induced RING-H2 domain protein) and TOPORS (topoisomerase I binding, arginine/serine rich), also reportedly bind to p53 and negatively regulate intracellular levels of p53 (Leng et al, 2003; Dornan et al, 2004a; Dornan et al, 2004b; Rajendra et al, 2004; 
Dornan et al, 2006; Wang et al, 2011). COP1 is reportedly overexpressed in breast, ovarian and hepatocellular carcinomas, and gastric cancer (Li et al, 2012) predictive of survival in the latter (Dornan et al, 2004b), suggesting it contributes to the accelerated degradation of the p53 protein and attenuating the tumour suppressor function of p53 (Dornan et al, 2004b). Silencing COP1 inhibits tumour growth and suggests COP1 may be a promising target for systemic therapy (Lee et al, 2010).

In contrast, COP1 also reportedly acts as a developmentally dependent tumour suppressor (Migliorini et al, 2011; Vitari et al, 2011), interacting with the oncoprotein c-Jun (Bianchi et al, 2003) to keep c-Jun at constitutively low levels in vivo and modulate c-Jun/AP-1 transcriptional activity in mice bred to be genetically hypomorphic at the COP1 locus (Migliorini et al, 2011). A COP1 deficiency also reportedly leads to c-Jun upregulation in human cancer cells (Migliorini et al, 2011), suggesting COP1 is also a tumour suppressor that functions, at least in part, by antagonising c-Jun oncogenic activity in the absence of a genetic interaction between COP1 and p53 (Migliorini et al, 2011). Here, we report the underlying mechanism for the post-translational increase in p53 $3^{\mathrm{wt}, \mathrm{mut}}$ levels induced by $\mathrm{p} 28$ in breast cancer and melanoma cells. p28 inhibits the binding of COP1 to a specific motif of the p53DBD, leading to an autoreduction in COP1 levels (Dornan et al, 2006) and an increase in the level of p53 in the absence of any alteration in c-Jun.

\section{MATERIALS AND METHODS}

Peptide synthesis. p28 (Leu ${ }^{50}$-Asp ${ }^{77}$ LSTAADMQGVVTDGMAS GLDKDYLKPDD, $2914 \mathrm{Da}$ ) was synthesised by C S Bio, Inc. (Menlo Park, CA, USA) at $>95 \%$ purity and mass balance.

Molecular dynamics. Computer simulations were performed essentially as described (De Grandis et al, 2007; Bizzarri et al, 2009). Configurations for azurin and the DBD of $\mathrm{p} 53$ were taken from 1E5Z and 1TUP of PDB files, respectively. The 28 aa of p28 was cut from the crystallographic structure for azurin and used to generate the configuration file subsequently applied to $\mathrm{MD}$ simulations at $300 \mathrm{~K}$ and $P=1$ bar. Complete details for $\mathrm{MD}$ are in the Supplementary Materials and Methods.

Docking studies. ClusPro (Kozakov et al, 2010) was used to conduct automated docking as a six-dimensional search within the rotational space between the two molecules. This generated a set of possible configurations for a predicted series of p53DBD-p28 complexes that were ranked based on scoring. The predicted complexes were then subjected to cluster analysis under a pairwise binding site root mean squared deviation criterion. The cluster model with the best score was used to further compare the proteinprotein interface using the ProtorP: Protein-Protein Interface Analysis Server (Reynolds et al, 2009).

Cell proliferation and xenograft tumour assays. Human breast cancer cells MCF-7, p53 ${ }^{\text {wt }}$ (ATCC, Manassas, VA, USA), the isogenic MDD2, p53 ${ }^{\text {dom/neg }}$ (Shaulian et al, 1992) (courtesy of Dr Andrei V. Gudkov, Roswell Park Cancer Institute, Buffalo, NY, USA) and MDA-MB-231, p53 ${ }^{\text {mut }}$, as well as normal breast (MCF$10 \mathrm{~A}, \mathrm{p} 53^{\mathrm{wt}}$ ) (ATCC) and melanoma cells (UISO-Mel-6, p53 ${ }^{\text {null }}$; UISO-Mel-23, p53 ${ }^{\text {mut }}$; UISO-Mel-29, p53 ${ }^{\mathrm{wt}}$ ) (Kichina et al, 2003) were cultured as described (Yamada et al, 2002; Punj et al, 2004; Taylor et al, 2009). p28 is a stable peptide that binds to p53 in the cell nucleus (Yamada et al, 2009) with intracellular concentrations reaching $120 \mathrm{ng} \mathrm{ml}^{-1}$ (p28) or $0.042\left(\mu \mathrm{moll}^{-1}\right) 2 \mathrm{~h}$ post exposure to $100 \mu \mathrm{moll}^{-1} \mathrm{p} 28$, which eliminated the need for repeated exposure. The effect of p28 on cell growth was determined by direct cell counting (Taylor et al, 2009).
Human melanoma (Mel-29, -23 and -6) and breast cancer cells (MCF-7 and MDA-MB-231) were injected s.c. in the right flank of 5- to 6-week-old male and female athymic mice (Punj et al, 2004; Jia et al, 2011; Mehta et al, 2011). When tumours reached $3 \mathrm{~mm}$ in diameter, animals were randomised into control (20 mice) and treatment (10 mice) groups, and injected i.p. with DTIC (5-(3,3dimethyl-1-triazeno) imidazole-4-carboxamide), $4 \mathrm{mg} \mathrm{kg}^{-1}, 3 \times$ /week (melanoma); paclitaxel, $12.8 \mathrm{mg} \mathrm{kg}^{-1}$ i.p., days 10, 14, 21 and 25 (breast cancer); or p28 10 or $20 \mathrm{mg} \mathrm{kg}^{-1}$ i.p. $3 \times /$ week for 30 days. Although p28 is rapidly cleared $\left(t_{1 / 2} 0.06 \mathrm{~h}\right.$; clearance $\left.\left(\mathrm{ml} \mathrm{kg}^{-1} \mathrm{~h}^{-1}\right) 2159\right)$, it is also rapidly taken up (Vdss $\left(\mathrm{ml} \mathrm{kg}^{-1}\right)$ 297) at pharmacologically active doses (Punj et al, 2004; Jia et al, 2011; Mehta et al, 2011). p28 is also stable in murine serum $\left(t_{1 / 2}\right.$ $60 \mathrm{~min}$ ) (Punj et al, 2004; Jia et al, 2011; Mehta et al, 2011) assuring a continuous release of the mature peptide. At necropsy, tumours were dissected, freed of fat and weighed. Statistical comparisons were performed by analysis of variance ANOVA (control vs treatment) (GraphPad InStat ver. 3.0, La Jolla, CA, USA).

Western blot analysis and RT-PCR. Human breast and melanoma cells were cultured with p28 at $50 \mu \mathrm{moll} \mathrm{l}^{-1}$ for $24-72 \mathrm{~h}$, whole-cell lysates prepared and western blot analysis conducted (Yamada et al, 2002; Yamada et al, 2009). A list of antibodies used is provided in Supplementary Materials and Methods. Band intensity was determined using UN-SCAN-IT (Silk Scientific Inc., Orem, Utah). Each control and experimental band was normalised by calculating the ratio of a specific protein/actin. Each experimental level was then expressed as the (relative) percentage of control.

Total RNA was extracted from human breast and melanoma cells exposed to p28, and RT-PCR conducted as previously described (Yamada et al, 2009). Primer sets are described under Supplementary Materials. Each control and experimental band was normalised by calculating the ratio of a specific gene/GAPDH. Each experimental level was then expressed as the (relative) percentage of control. The data are representative of at least two independent measures.

Construction and purification of p53 fragments. Plasmid pGEX5X3 (GE Healthcare, Little Chalfont, United Kingdom) expressing GST fused to fragments of human $\mathrm{p} 53^{\mathrm{wt}}$ were constructed by PCR (Yamada et al, 2009). DNA fragments encoding aa 1-80, 81-300, 81-160, 161-300 and 301-393 of p53 were amplified with specific primer sets (Supplementary Materials and Methods) and GST-fusion proteins purified by Glutathione Sepharose 4B affinity chromatography and HiLoad Superdex 75 gel-filtration column connected to the ÄKTAprime plus FPLC system (GE Healthcare) (Yamada et al, 2009).

GST pull-down assays. p28 binding to fragments of p53 was analysed using a GST pull-down assay (Yamada et al, 2009). GST fused to fragments of p53 and GST alone were bound to glutathione-Sepharose 4B beads (GE Healthcare), p28 added and incubated for $2 \mathrm{~h}$. Each sample was loaded on $6 \%$ native-PAGE. Membranes were incubated with polyclonal anti-p28 antibody, washed three times with Tris- $\mathrm{HCl}$ containing $0.05 \%$ Tween 20, secondary rabbit IgG-HRP antibody (Sigma-Aldrich, St Louis, MO, USA). COP1 binding to $\mathrm{p} 53$ in the presence or absence of p28 was analysed using competitive pull-down assays (Hosaka et al, 2005). GST fused to fragments of p53 were immobilised on beads, followed by incubating with or without p28 (10-100 mole excess). Whole-cell lysates containing COP1 were prepared from MCF-7 cells in PBS containing $0.1 \%$ Triton X-100, $10 \%$ glycerol and a protease inhibitor cocktail (Sigma-Aldrich). Soluble extracts were incubated with beads, each sample washed with PBS, pelleted and analysed with an anti-COP1 antibody. 


\section{RESULTS}

Docking simulation of p28-p53 complex. ClusPro identified motifs spanning the $\mathrm{L}_{1}$ loop (aa 112-124), within aa 139-146, a region within the $S_{7}-S_{8}$ loop (aa 214-236) and R282 and L289 of the p53 DBD ( $\mathrm{Tu}$ et al, 2008) that were involved in the binding between p28 and p53 (Figure 1A). Molecular surface and electrostatic potential plots of the p53DBD were calculated by DeepView ver. 4.0.3 (Swiss Institute of Bioinformatics, Geneva, Switzerland) (Figure 1B). A blue, red and white colour gradient represents positive, negative and neutral (including hydrophobic aa) potentials on the molecular surface, respectively. The DNAbinding surface of the p53DBD is highly cationic (blue). In contrast, the p28-binding area is essentially neutral (white), suggesting that electrostatic interaction may not have a role in p28 binding to p53 (Figure 1B). The amino-acid composition of the predicted p28-binding sites on p53 was FLHSGTAVTCTYPA LTPQWEGSDCTHRL or $43 \%$ hydrophobic, 36\% neutral and $21 \%$ hydrophilic residues. p28 bound to 10 of 13 aa (77\%) in the $\mathrm{L}_{1}$ loop that were $50 \%$ hydrophobic, $40 \%$ neutral and $10 \%$ hydrophilic residues and 7 of 23 aa (30\%), 14\% hydrophobic, $43 \%$ neutral and $43 \%$ hydrophilic, in the $\mathrm{S}_{7}-\mathrm{S}_{8}$ loops (Figure 1C). The four amino acids residing between residues 139 and 147 predicted to bind p28 are $50 \%$ hydrophobic and $50 \%$ neutral. These residues and the $\mathrm{L}_{1}$ and $\mathrm{S}_{7}-\mathrm{S}_{8}$ loops are not located at or near the DNA-binding surface of p53 (R248 and R273 are direct DNA-binding residues on p53), suggesting p28 does not interfere with the ability of p53 to bind to DNA (Figure 1B). The ClusPro best score model also predicted that amino-acid residues LSTAAMQVVGDYLKDD of p28 bind to p53. Fifty per cent of the predicted residues are hydrophobic, again suggesting that hydrophobic rather than electrostatic interaction is essential to the formation of the p28-p53 complex (Figure 1B). These results agree with computational docking (De Grandis et al, 2007) studies demonstrating that azurin binds to the $\mathrm{L}_{1}$ and $\mathrm{S}_{7}-\mathrm{S}_{8}$ loops of $\mathrm{p} 53$ through interaction of non-polar residues at the interface, creating a short-range hydrophobic interaction. A sequence map of the amino acids predicted to be involved in 28 binding and their relationship to the known binding sites of the E3 ubiquitin ligases that negatively regulate p53 is illustrated in Figure 1D. p28 does not bind to motifs shown to bind either HDM2 or Pirh2.

GST pull-down assays. p28-binding regions on p53 were mapped using a GST pull-down assay (Yamada et al, 2009). GST-p53 $3_{1-393}$ (full length p53), GST-p53 ${ }_{81-300}$ (p53DBD), GST-p53 $81-160$ and GST-p53 $161-300$ pulled down p28, but the N- (GST-p53 $1-80$ ) and C-terminus of p53 (GST-p53 $301-393$ ) and GST alone did not (Figure 2A). These results confirm computerised predictions of regions within the DBD of p53 likely to bind p28 (Figure 1A-D). We confirmed that binding motifs for p 28 and COP1 overlap using competitive pull-down assays of purified GST-p53 and GST alone in the presence of excess p28. p28 induced a significant concentration-dependent reduction in the amount of COP1
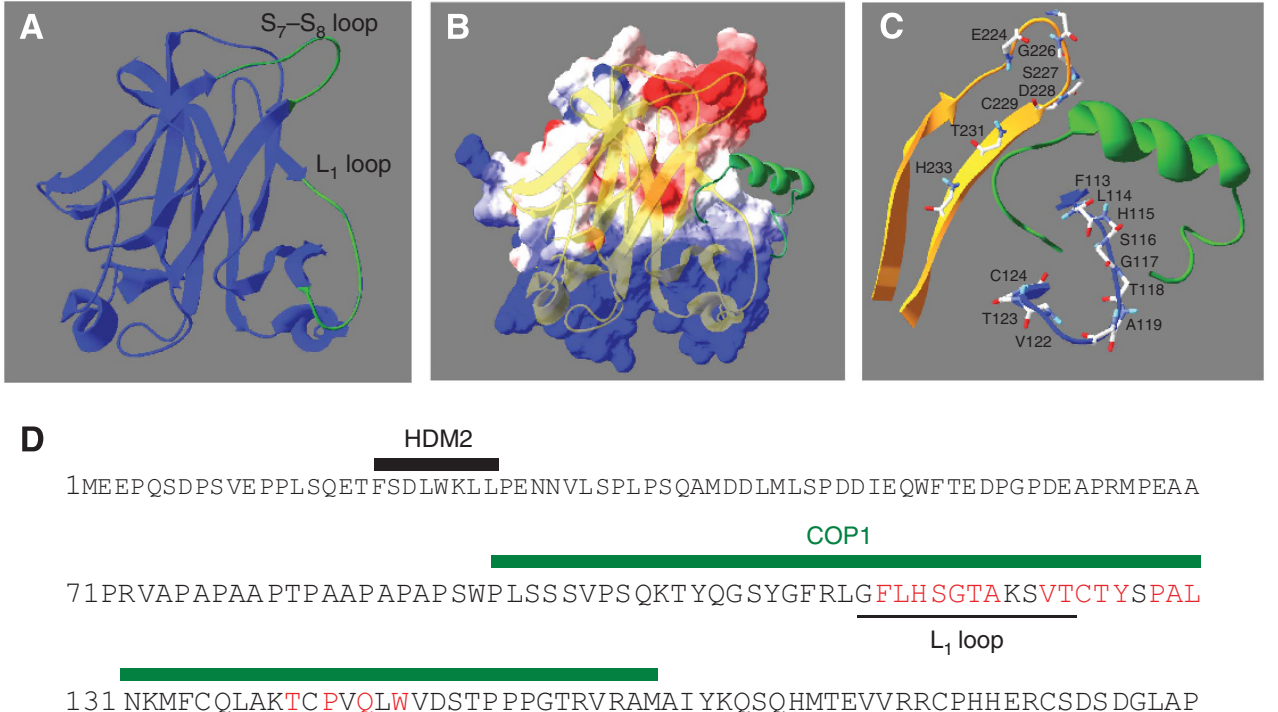

191PQHLI RVEGNL RVEYL DDRNT FRHSVVVPYEP PEVGS DCTT I H YNYMCN S SCMGGMNRRP

$$
\mathrm{S}_{7}-\mathrm{S}_{8} \text { loop }
$$

251 ILTI I TLEDS S GNLLGRNSFEVRVCAC PGRDRRTEEENLRKKGEPHHEL PPGSTKRALSN

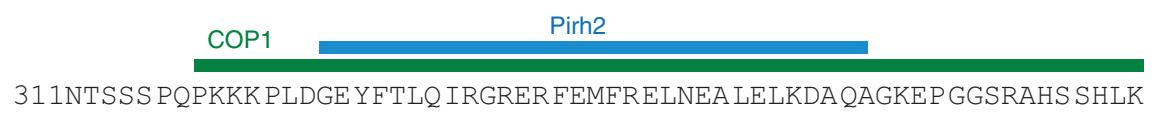

371SKKGQSTSRHKKLMFKTEGP DSD

Figure 1. Docking model of p28 and p53. (A) The p28-p53 complex structure obtained from the best docking model. Blue: overall ribbon diagram of the p53DBD, green: $L_{1}$ and $S_{7}-S_{8}$ loops. (B) Ribbon diagram of the p53DBD (yellow) superimposed on the electrostatic potential plot. p28 (green) binds to hydrophobic pocket. (C) Relationship of p28 (green) and $\mathrm{L}_{1}$ (blue) and $\mathrm{S}_{7}-\mathrm{S}_{8}$ (yellow) loops of the p53DBD. (D) Map of E3 ligase binding regions superimposed on the full-length sequence of p53. p28-binding residues indicated in red. Binding regions of HDM2, COP1 and Pirh2 indicated in black, green and blue bars, respectively. COP1 binds to p53 in regions separate from HDM2. p28 and COP1 share a binding motif within aa 92-160 of the p53DBD. 

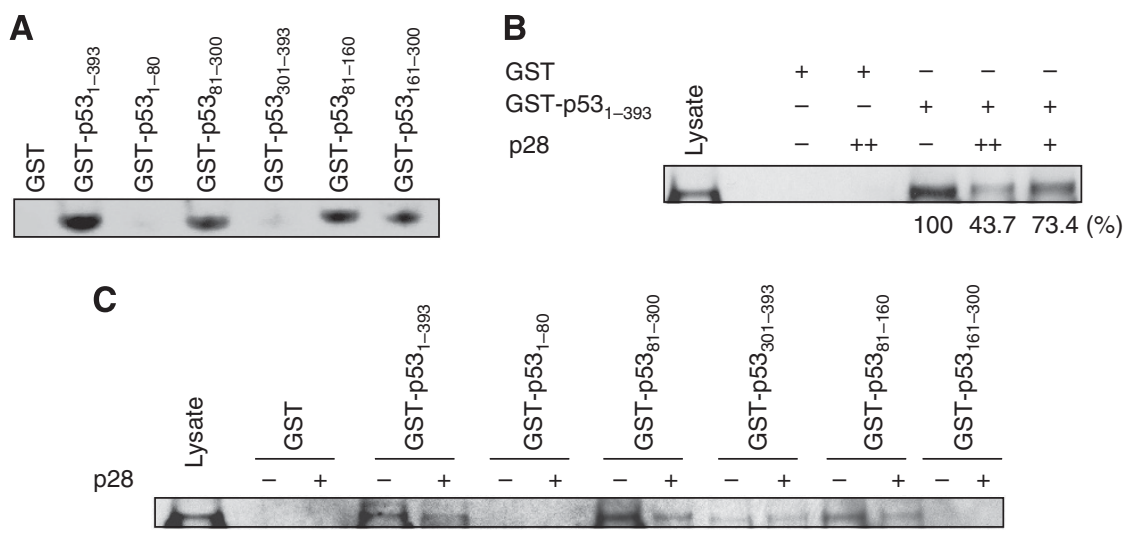

Figure 2. p28-binding regions on p53. (A) Purified various fragments of p53 and GST alone were used for a GST pull-down assay. Each sample was analysed by immunoblotting with an anti-p28 antibody. (B) Competitive pull-down assay. Immobilised GST-p531-393 and GST alone on glutathione-Sepharose 4B beads were incubated in absence $(-)$ or presence of p28 $(+: 10,++: 100$ mole excess), followed by adding MCF-7 lysates containing COP1. Samples were separated by SDS-PAGE and immunoblotted with an anti-COP1 antibody. Lysate: whole-cell lysates of MCF-7 used for the assay showed the stable expression of COP1. Numbers below COP1 bands were relative percentage to the level of COP1 bound to p53 in absence of p28. (C) COP1 binding to various fragments of p53 in absence or presence of p28 was analysed using a similar competitive pull-down assay. Immobilised various fragments of p53 and GST alone were treated with or without p28 (100 mole excess), followed by incubation with MCF-7 lysates containing COP1.

binding to the DBD of p53 (Figure 2B). Fine mapping of the regions within the $\mathrm{p} 53 \mathrm{DBD}$ revealed that $\mathrm{p} 28$ inhibited the binding of COP1 to only GST-p5 $3_{81-300}$ and GST-p53 $3_{81-160}$, clearly demonstrating that $\mathrm{p} 28$ inhibits the binding of COP1 to p53 only where their respective binding sites overlap (Figure 2C).

Effect of $\mathbf{2 8}$ on the growth of human cancer cells. p28 produces a time and dose-related inhibition of $\mathrm{p} 53^{\mathrm{wt}}$ tumour cell and xenograft growth (Yamada et al, 2009; Jia et al, 2011). Figure 3A shows that a 72 -h exposure to p28 at $50 \mu \mathrm{moll}^{-1}$ decreased the proliferation of ( $\left.553^{\mathrm{wt}}\right)$ Mel-29 and (p53 $\left.{ }^{\mathrm{mut}}\right)$ Mel-23, where p53 is internally deleted at aa 178-183 (Kichina et al, 2003), 25-30\% from control. The inhibition was similar to that of $50 \mu \mathrm{moll}^{-1}$ DTIC. Neither p28 nor DTIC altered the proliferation of p53 null Mel-6 cells. p28 also exhibited significant cytostatic activity on p53 ${ }^{\text {wt }}$ MCF-7 breast cancer cells with a similar reduction $(\sim 20 \%)$ in the number of ( $\left.\mathrm{p} 53^{\text {mut }} \mathrm{R} 280 \mathrm{~K}\right)$ MDA-MB-231 cells after $72 \mathrm{~h}$ (Figure 3B). These observations, in contrast, p28 did not exhibit an antiproliferative effect on MDD2 (p53 ${ }^{\text {dom/neg }}$ ) or normal MCF-10A $\left(\mathrm{p} 53^{\mathrm{wt}}\right.$ ) mammary cells confirming previous results (Yamada et al, 2009). Paclitaxel at $50 \mu \mathrm{moll}^{-1}$ inhibited the growth of MCF-7 and MDA-MB-231 breast cancer cells by $\sim 90 \%$ and MDD2 $\left(\mathrm{p} 53^{\mathrm{dom} / \mathrm{neg}}\right.$ ) and MCF-10 A (p53 ${ }^{\mathrm{wt}}$ ) cells by $\sim 50 \%$ and $35 \%$, respectively (Figure $3 \mathrm{~B}$ ). p28 also significantly decreased the weight of established p53 ${ }^{\mathrm{wt}}$ Mel-29 and p53 ${ }^{\text {mut }}$ Mel-23 xenograft tumours in athymic mice (Figure 3C). p28 did not inhibit cell growth of p53 ${ }^{\text {null }}$ Mel-6 in vitro (Figure 3A) or in vivo (Figure 3C). p28 also decreased the weight of MCF-7 (p53 ${ }^{\mathrm{wt}}$ ) and MDA-MB-213 (p53 ${ }^{\text {mut }}$ ) xenograft tumours by $\sim 50$ and $60 \%$ respectively, similar to the effect of a non-toxic dose of paclitaxel (Mi et al, 2002) (Figure 3D). The significant reduction in growth at $20 \mathrm{mg} \mathrm{kg}^{-1}$ and lack of effect at $10 \mathrm{mg} \mathrm{kg}^{-1}$ on MDA-MB-231 cells contrast sharply with the similarity in effect for either dose of p28 on p53 ${ }^{\mathrm{wt}}$ MCF-7, Mel-29 or p53 ${ }^{\text {mut }}$ Mel-23 cells, suggesting the site of the mutation may be critical to overexpression of $\mathrm{p} 53$ (Figures 4A and 5A) and to the overall effect of p28 on the proliferation of $\mathrm{p} 53^{\mathrm{mut}}$ cancer cells.

p28 Alters the level of p53 and major downstream targets. The significant decrease in growth following exposure to p28 was associated with a sustained increase in the level of p53 in p53 MCF-7 and p53 ${ }^{\text {mut }}$ MDA-MB-231 cells (Figure 4A) and p53 ${ }^{\text {wt }}$ Mel-29 and p53 ${ }^{\text {mut }}$ Mel-23 cells (Figure 5A) with no alteration in the level of transcription of p53 (Figures 4B and 5B), confirming earlier results of an increase in $\mathrm{p} 53^{\mathrm{wt}} \mathrm{MCF}-7$ cells in response to p28 (Yamada et al, 2009). The increase in the level of p53 protein in these lines was also directly associated with an increase in the level of transcription and translation of p21. p28 did not alter either the level or rate of transcription of $\mathrm{p} 53$ or $\mathrm{p} 21$ in $\mathrm{p} 53^{\mathrm{dom} / \mathrm{neg}}$ MDD2, p53 ${ }^{\mathrm{wt}}$ normal MCF-10A or p53 ${ }^{\text {null }}$ Mel-6 cells (Figures $4 \mathrm{~A}$ and $\mathrm{B}$, and $5 \mathrm{~A}$ and $\mathrm{B}$ ). Forkhead box M1 protein (FoxM1), an important regulator of the $\mathrm{G}_{2}-\mathrm{M}$ transition, was significantly reduced in MCF-7, Mel-29 and Mel-23 cells during exposure to $\mathrm{p} 28$, increased in $\mathrm{p} 53^{\mathrm{dom} / \text { neg }} \mathrm{MDD} 2$ cells at $48-72 \mathrm{~h}$, and remained essentially unchanged in MDA-MB-231, MCF-10A and Mel-6 cells, suggesting that downregulation of FoxM1 also contributed to inhibition of the cell cycle in p53 $3^{\mathrm{wt}}$ MCF-7, Mel-29 and $\mathrm{p} 53^{\mathrm{mut}}$ Mel-23 cells. Although this may result from an inability of p53 $3^{\text {mut }}$ to bind the p53 canonical consensus regions in the FOXM1 promoter, p21 levels were sufficiently elevated to inhibit the proliferation of $\mathrm{p} 53^{\text {mut }}$ MDA-MB-231 cells, despite the overexpression of FoxM1 (Figure 4A) (Bektas et al, 2008). This is not surprising because p53 mutants can often transactivate promoters containing a p21 responsive element (Campomenosi et al, 2001) and loss of function in mutant p53 breast tumours does not represent a complete absence of activity (Williams et al, 1998). STMN1, an inhibitor of microtubule polymerisation (Belmont and Mitchison, 1996) and critical for cell cycle progression, was not significantly decreased in any cancer cell line tested (Figures $4 \mathrm{~A}$ and $5 A$ ), suggesting p28 inhibition of the cell cycle at $G_{2}-M$ is at $\mathrm{G}_{2}$ and does not involve inhibition of microtubule formation.

The p28-induced increase in p53 was associated with a significant decrease in the levels of COP1 in $\mathrm{p} 53^{\mathrm{wt}}$ and $\mathrm{p} 53^{\mathrm{mut}}$ breast cancer and melanoma cells (Figures 4A and 5A). Exposure of $553^{\mathrm{wt}}$ MCF-7 and p53 ${ }^{\mathrm{mut}}$ MDA-MB-231 cells to $\mathrm{p} 28$ reduced COP1 levels by $\sim 70 \%$ and $80 \%$, respectively, over $24-72 \mathrm{~h}$ without altering the transcription of COP1 (Figure 4A). Exposure of p53 $3^{\mathrm{wt}}$ Mel-29 to p28 significantly reduced COP1 levels $(\sim 75 \%)$ at $24 \mathrm{~h}$ that gradually increased ( $\sim 60 \%$ of control) at $72 \mathrm{~h}$ (Figure $5 \mathrm{~A}$ ). A similar effect on COP1 levels was observed in p53 ${ }^{\text {mut }}$ Mel-23 cells. The lack of effect of p28 on COP1 levels in p53 ${ }^{\text {null }}$ Mel- 6 and delayed increase in $\mathrm{p} 53^{\mathrm{dom} / \mathrm{neg}} \mathrm{MDD} 2$ exposed to $\mathrm{p} 28$ suggest that the effects of p28 on COP1 are a function of a cell's p53 status. Moreover, as continued exposure to p28 does not significantly alter COP1 transcription in $\mathrm{p} 53^{\mathrm{wt}}$ and $\mathrm{p} 53^{\mathrm{mut}}$ cancer cells, the decrease 

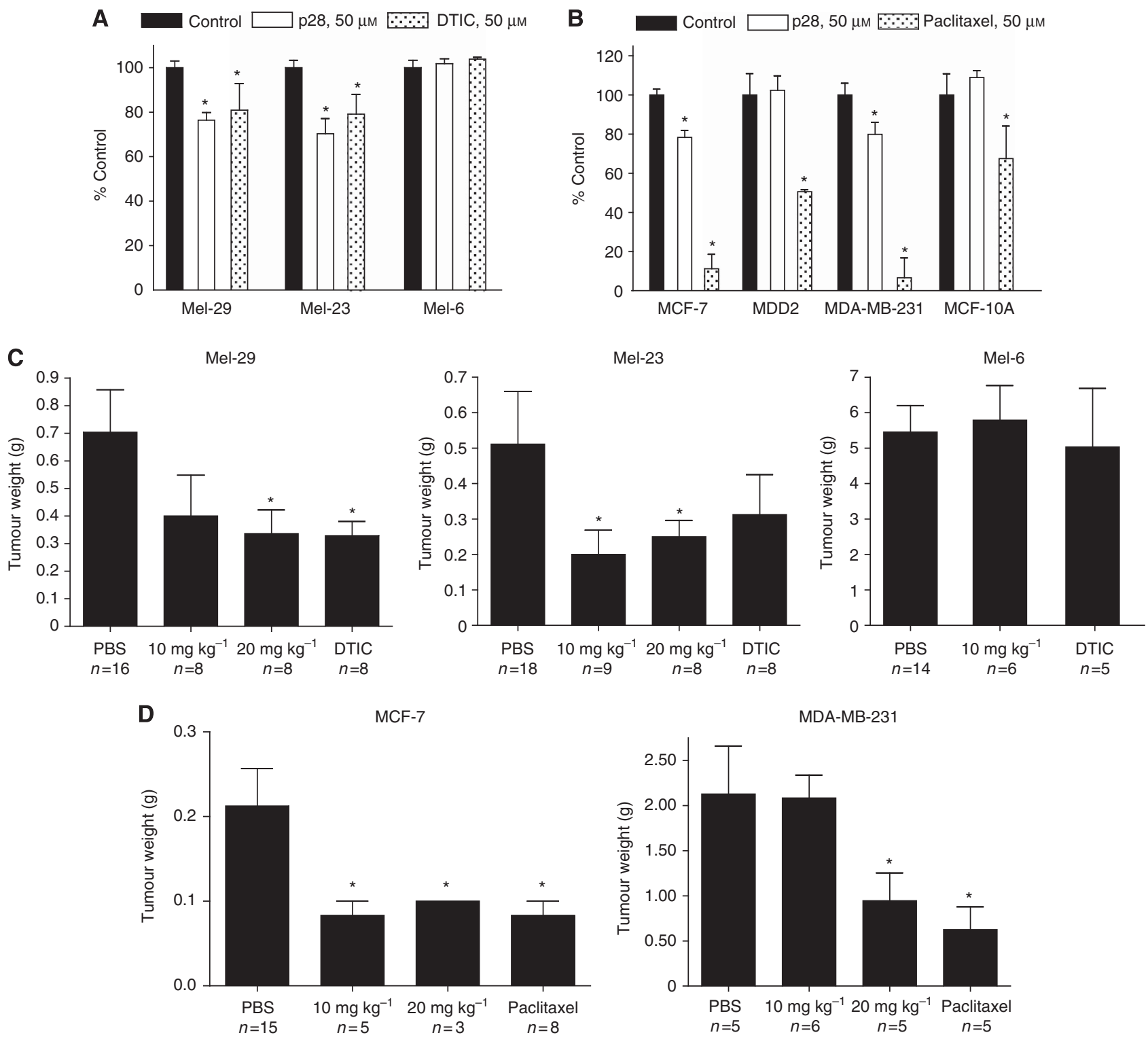

Figure 3. The effect of p28 on cell and xenograft growth. Human melanoma UISO-Mel-29, -23 and -6 (A) and breast cancer MCF-7, MDD2, MDA-MB-231 and normal MCF-10A cells (B) were exposed to p28, DTIC, paclitaxel or a similar volume of media without peptide for $72 \mathrm{~h}$ and cells counted. Values represent the mean \pm s.d. of three replicates. Reduction in Mel-23, 29 xenograft growth (C). Reduction of MCF-7, MDA-MB-231 xenograft growth (D). ${ }^{\star} P<0.05$.

in the overall level of COP1 likely occurs through autodegradation (Dornan et al, 2006).

p28 Effects on minor E3 ubiquitin ligases. p28 produces a posttranslational increase in p53 through decreased ubiquitination and proteasomal degradation rather than transcriptional activation (Yamada et al, 2009). However, exposure to p28 transiently increased the transcription and level of TOPORS $(48 \mathrm{~h})$ in $\mathrm{p} 53^{\mathrm{wt}}$ MCF-7 cells, but did not significantly affect either the transcription or level of TOPORS in p53 ${ }^{\text {mut }}$ MDA-MB-231 cells (Figure $4 \mathrm{~A}$ and B). This suggests the upregulation of TOPORS by wild-type p53 was more efficient than with mutated p53. Exposure of p53 ${ }^{\mathrm{wt}} \mathrm{Mel}-$ 29 cells to p28 produced a sustained increase in the level of TOPORS that was not transcription dependent, whereas exposure of $\mathrm{p} 53^{\text {mut }}$ Mel-23 cells to $\mathrm{p} 28$ reduced the level of TOPORS over $48 \mathrm{~h}$, which was not preceded or accompanied by a change in transcription (Figure $5 \mathrm{~A}$ and $\mathrm{B}$ ). The increase in the level and transcription of TOPORS in p53 ${ }^{\mathrm{wt}}$ MCF-7 and Mel-29 cells and lack of effect on $\mathrm{p} 53^{\text {mut }}$ MDA-MB-231 and Mel-23 cells suggest that changes in the level of TOPORS in response to p28 are dependent on p53 status and do not have a major role in the regulation of cell proliferation.

p28 also induced a short-term $(24 \mathrm{~h})$ increase in the level of Pirh2 in p53 ${ }^{\mathrm{wt}}$ MCF-7 and MDA-MB-231 cells without an accompanying increase in transcription, suggesting that the transient increase was in response to the p28-induced increase in p53 (Figure 4A and B). In contrast, p28 had no significant effect on the expression of the Pirh2 protein or transcription in $\mathrm{p} 53^{\mathrm{wt}}$ Mel29 or p53 ${ }^{\text {mut }}$ Mel-23 cells (Figure 5A and B). Collectively, changes in the level of TOPORS and Pirh2 appeared dependent on the cell line treated as well as p53 status and are a minor factor in the regulation of wild-type or mutated $\mathrm{p} 53$.

In contrast, the initial increase $(24-48 \mathrm{~h})$ and slow rise $(72 \mathrm{~h})$ in the level of the major E3 ligase HDM2 in $\mathrm{p} 53^{\mathrm{wt}} \mathrm{MCF}-7$ and $\mathrm{p} 53^{\mathrm{mut}}$ MDA-MB-231 cells, respectively, was accompanied by a parallel increase in transcription. However, neither increase reflected the 


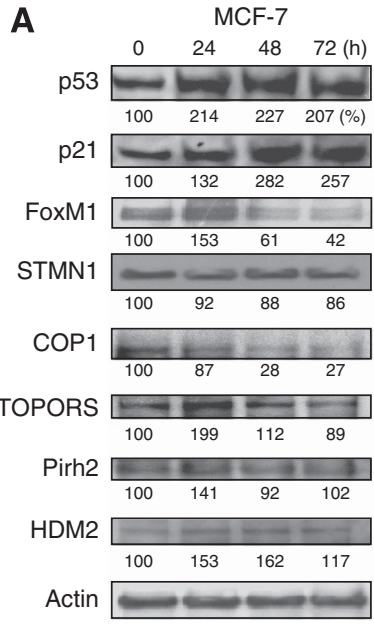

B

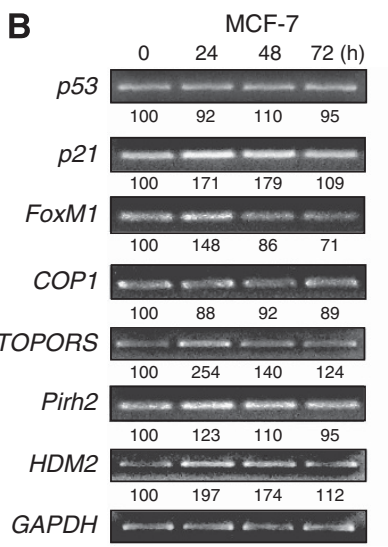

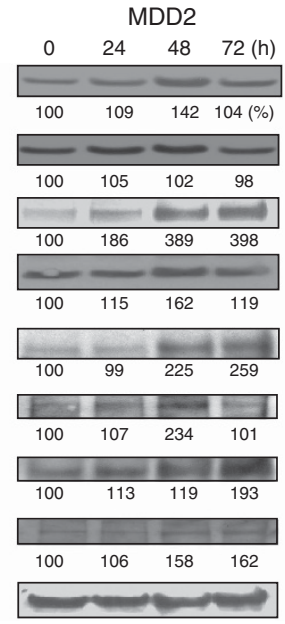

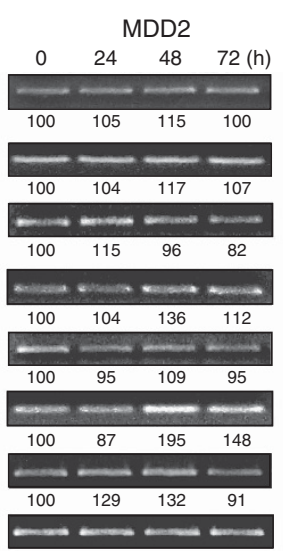

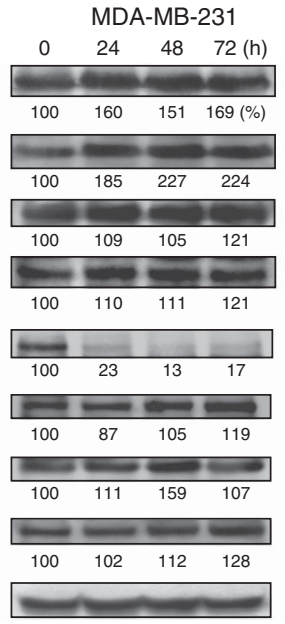
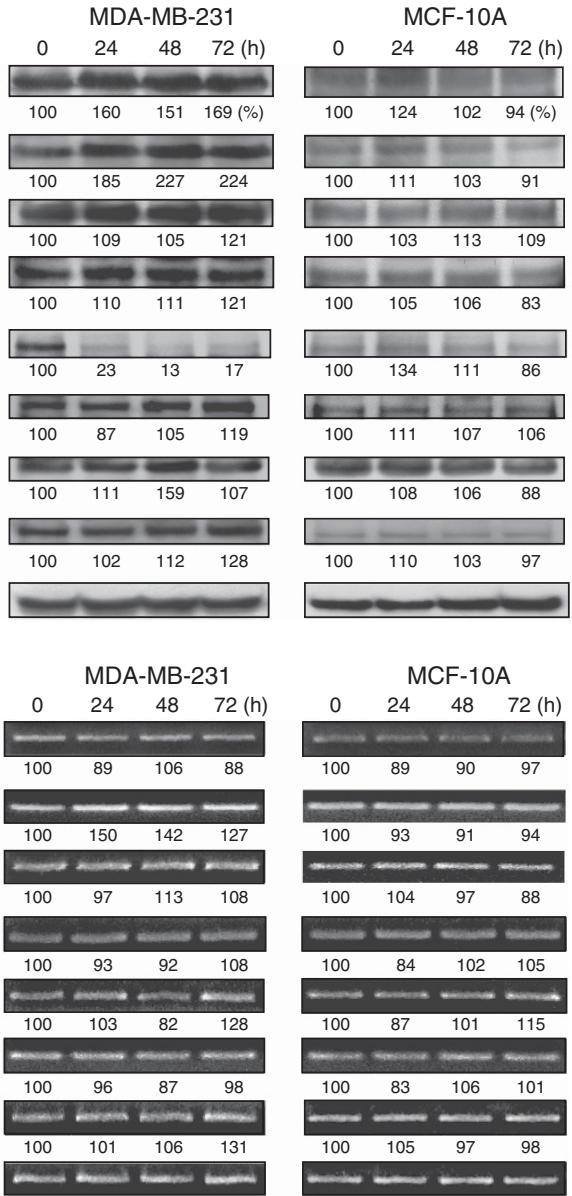

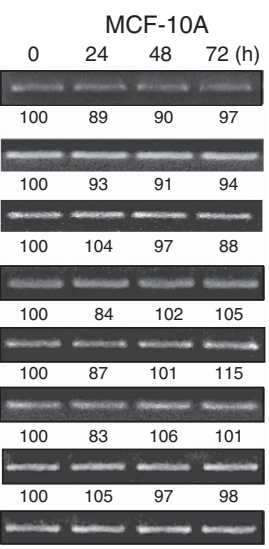

Figure 4. Stabilisation of p53 by E3 ligases on $553^{\text {wt, mut }}$ breast cancer cells. (A) MCF-7, MDD2, MDA-MB-231, and MCF-10A cells were treated with p28 at $50 \mu \mathrm{moll} \mathrm{I}^{-1}$ for 24-72 h. Whole-cell lysates were subjected to western blot analysis. (B) The expression of each gene was determined by RT-PCR. The numbers indicated below each band represent the relative to control (control expressed as $100 \%)$.

sustained increase in $\mathrm{p} 53$ in response to p28. Unlike COP1, HDM2 levels were not significantly altered by 28 in p $53^{\text {wt }}$ Mel-29 cells, but increased late in exposure $(48-72 \mathrm{~h})$ in $\mathrm{p} 53^{\text {mut }}$ Mel-23 (Figure 5A).

p28 Effect on c-Jun. If COP1 acts as a developmentally dependent tumour suppressor (Migliorini et al, 2011; Vitari et al, 2011), interacting with the oncoprotein c-Jun (Bianchi et al, 2003) to keep c-Jun at constitutively low levels in vivo and COP1 deficiency leads to c-Jun upregulation in human cancer cells (Migliorini et al, 2011) even in the absence of a genetic interaction between COP1 and p53 (Migliorini et al, 2011), then exposure to p28 should significantly increase c-Jun levels in p53 $3^{\text {wt,mut,null }}$ cells. p28 did not significantly alter the level of c-Jun in either p53 ${ }^{\mathrm{wt}}$ MCF-7, MDD2 or MCF-10A cells and transiently $(48 \mathrm{~h})$ reduced $(38 \%)$ c-Jun levels in p53 $3^{\text {mut }}$ MDA-MB-231 breast cancer cells (Figure 6A). In contrast, c-Jun was significantly decreased over $48-72 \mathrm{~h}$ in $\mathrm{p} 53^{\mathrm{wt}}$ Mel-29 cells, briefly increased $(48 \mathrm{~h})$ in $\mathrm{p} 53^{\mathrm{mut}} \mathrm{Mel}-23$ cells, and only increased slightly over $24 \mathrm{~h}$ in p53 ${ }^{\text {null }}$ Mel-6 cells (Figure 6C). The decrease in c-Jun in p53 ${ }^{\mathrm{wt}}$ Mel-29 cells was accompanied by an increase in transcription $(72 \mathrm{~h})$, suggesting the increase was in response to the decrease in the level of the c-Jun protein (Figure 6B and D) rather than the result of a decrease in COP1 following exposure to p28. None of these results suggest that a sustained decrease in COP1 results in an increase in the level and transcription of c-Jun (Migliorini et al, 2011).

Moreover, the absence of any change in p53, COP1, p21, FOXM1, TORPORS, Pirh2 or HDM2 and the transient increase in
c-Jun in p53 ${ }^{\text {null }}$ Mel-6 cells in response to p28 suggest that the antiproliferative effects of p28 are mediated via the sustained increase in p53 and p21 independent of any effect on c-Jun (Migliorini et al, 2011).

\section{DISCUSSION}

Although most wild-type or mutated p53 tumours must certainly be dysfunctional (Wiman, 2006), cancer cells proliferate irrespective of p53 status. This suggests reactivation of p53-induced control of the cell cycle and apoptosis is a plausible therapeutic goal regardless of p53 status. The loss of wild-type p53 function or gain of new oncogenic properties may result, in part, from the numerous missense point mutations within the DBD of p53 clustered into discrete hot spots (R175, G245, R248, R249, R273 and R282) (Tu et al, 2008). However, the reported gain-of-function properties reportedly associated with p53 hot spot mutations may not be a universal phenomenon (Lee et al, 2012). Amino-acid residues R248 and R273 directly contact DNA while the remainder stabilises the structure of the DNA-binding motif within the DBD (Tu et al, 2008). In contrast, the flexible $\mathrm{L}_{1}$ loop (aa 112-124) within the p53DBD is a mutational cold spot (Zupnick and Prives, 2006). Our models predicted that $\mathrm{p} 28$ would bind to the $\mathrm{L}_{1}$ loop, a region of the $S_{7}-S_{8}$ loop (aa 214-236) and T140, P142, Q144, W146, R282 and L289 of the p53DBD. This prediction was supported by GST pull-down assays (Figure 2A) and atomic force 
A

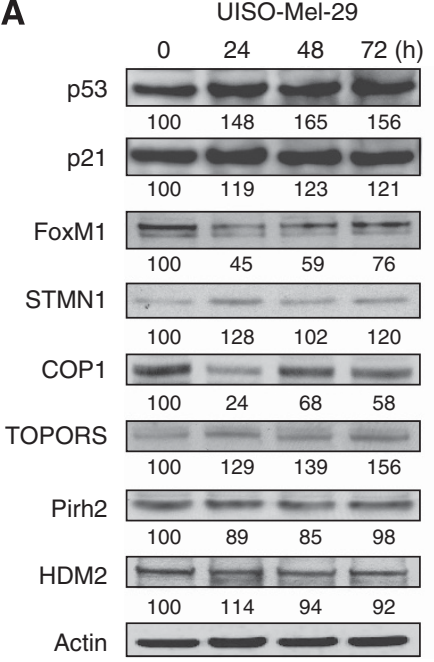

B

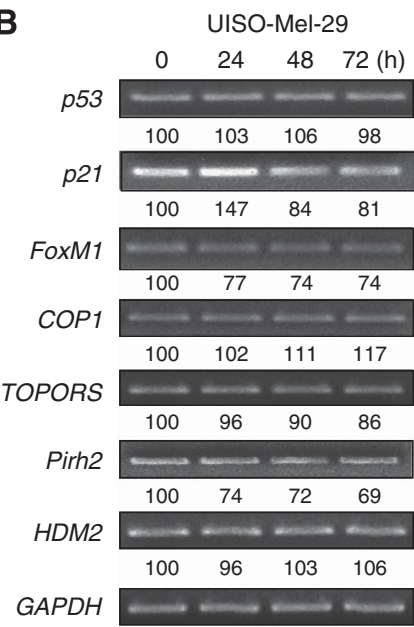

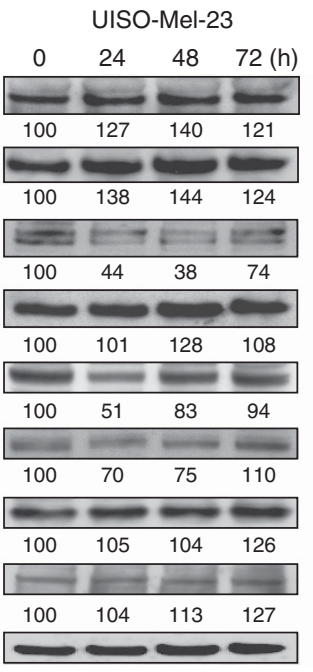

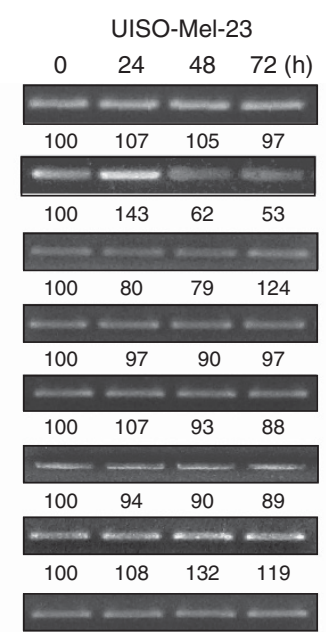

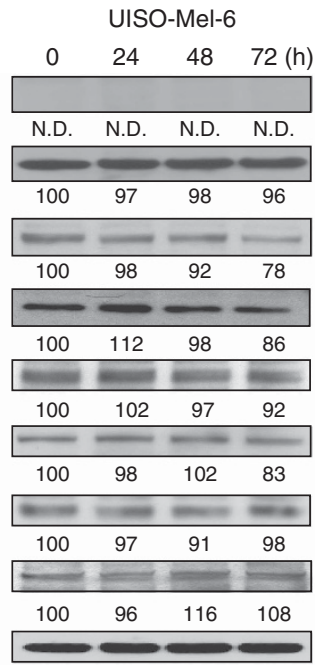

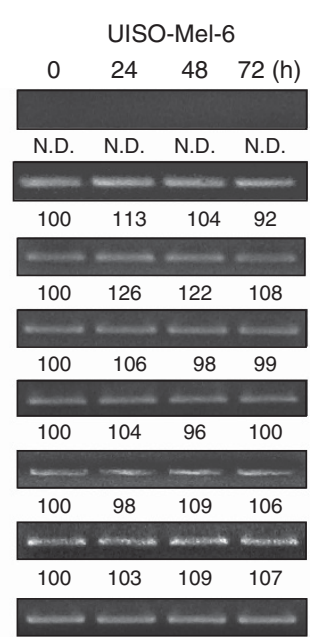

Figure 5. Stabilisation of p53 by E3 ligases on p53 $3^{\text {wt,mut }}$ melanoma cells. (A) Mel-29, Mel-23 and Mel-6 cells were treated with p28 at $50 \mu$ mol I ${ }^{-1}$ for $24-72 \mathrm{~h}$. (B) The expression of each gene was determined by RT-PCR. The numbers indicated below each band represent the relative to control (control expressed as 100\%).

spectroscopy studies that indicated p28 binds with high affinity to the p53DBD (Bizzarri et al, 2011).

Once bound, p28 produces an increase in the level of p53 $3^{\mathrm{wt}, \mathrm{mut}}$ (Figures 4A and 5A), which is associated with an inhibition of cell proliferation in vitro and in vivo (Figure $3 \mathrm{~A}-\mathrm{D}$ ). Neither the internal in frame deletion (aa 178-183) (Kichina et al, 2003) in p53 in Mel-23 cells, which does not include the predicted binding sites for $\mathrm{p} 28$, nor the point mutation at R280K in MDA-MB-231 cells that leads to overexpression (Olivier et al, 2002) (Figure 4A) affects the binding of $\mathrm{p} 28$. This suggests that increasing an already elevated level of mutated p53 may also positively impact downstream targets within the cell cycle and apoptotic pathways (Ludwig et al, 1996; Campomenosi et al, 2001).

The FoxM1, a transcription factor for genes regulating the $\mathrm{G}_{2}-$ $\mathrm{M}$ transition, is a major downstream target of p53 (Laoukili et al, 2005). Loss of FoxM1 leads to a delay in $\mathrm{G}_{2}$ (Laoukili et al, 2005). p28 reduced the level of FoxM1 in p53 ${ }^{\mathrm{wt}}$ MCF-7, p53 ${ }^{\mathrm{wt}}$ Mel-29 and p53 ${ }^{\text {mut }}$ Mel-23 cells and inhibited cell proliferation, but did not reduce the high basal levels of FoxM1 in triple negative (ER ${ }^{-}$, $\mathrm{PGR}^{-}, \mathrm{HER}^{-}{ }^{-}$) $\mathrm{p}^{\mathrm{mut}}{ }^{\mathrm{mu}}$ MDA-MB-231 cells (Figure 4A). The significant inverse correlation between FoxM1 expression and human epidermal growth factor 2 (HER2) (Bektas et al, 2008) suggests overexpression of FoxM1 may result from this interaction or that the $\mathrm{p} 53^{\text {mut }} \mathrm{R} 280 \mathrm{~K}$ in MDA-MB-231 cells may not allow binding to the promoter region of FoxM1. However, p28 did increase the level of p21 in p53 ${ }^{\text {mut }}$ MDA-MB-231 cells (Figure 4A), in turn inhibiting the activity of the cyclin-CDK2 complex (Yamada et al, 2009). This suggests that inhibition of CDK by p21 provided an alternative pathway for the reduction in growth in the absence of a reduction in FoxM1.

Intracellular levels of p53 are tightly regulated by a series of ubiquitin E3 ligases that promote ubiquitination and proteasomedependent degradation of p53 (Michael and Oren, 2003). HDM2 or MDM2 is the major E3 ligase promoting p53 degradation (Haupt et al, 1997; Kubbutat et al, 1997), but TOPORS, Pirh2 and particularly COP1 also bind to and negatively regulate p53 (Leng et al, 2003; Dornan et al, 2004b; Rajendra et al, 2004). Although TOPORS is expressed in most normal human tissues (Saleem et al, 2004), it is not expressed in colon cancer (Rajendra et al, 2004) and may not be an E3 ligase critical to p53 function in malignant cells. In contrast, Pirh2 expression is lower in normal compared with tumour cells and appears independent of the type of p53 mutation (Duan et al, 2006). The C-terminal domain of Pirh2 (aa 190-261) binds primarily to the tetramerisation domain (aa 325-355) of p53 (Sheng et al, 2008) well removed from the binding sites for p28. Exposure to p28 did not reduce Pirh2 levels in either breast cancer or melanoma cells (Figures 4 and 5), producing only short-term increases that were not accompanied by an increase in transcription. This suggests that only extant Pirh2 was recruited to degrade the increasing levels of p53. 


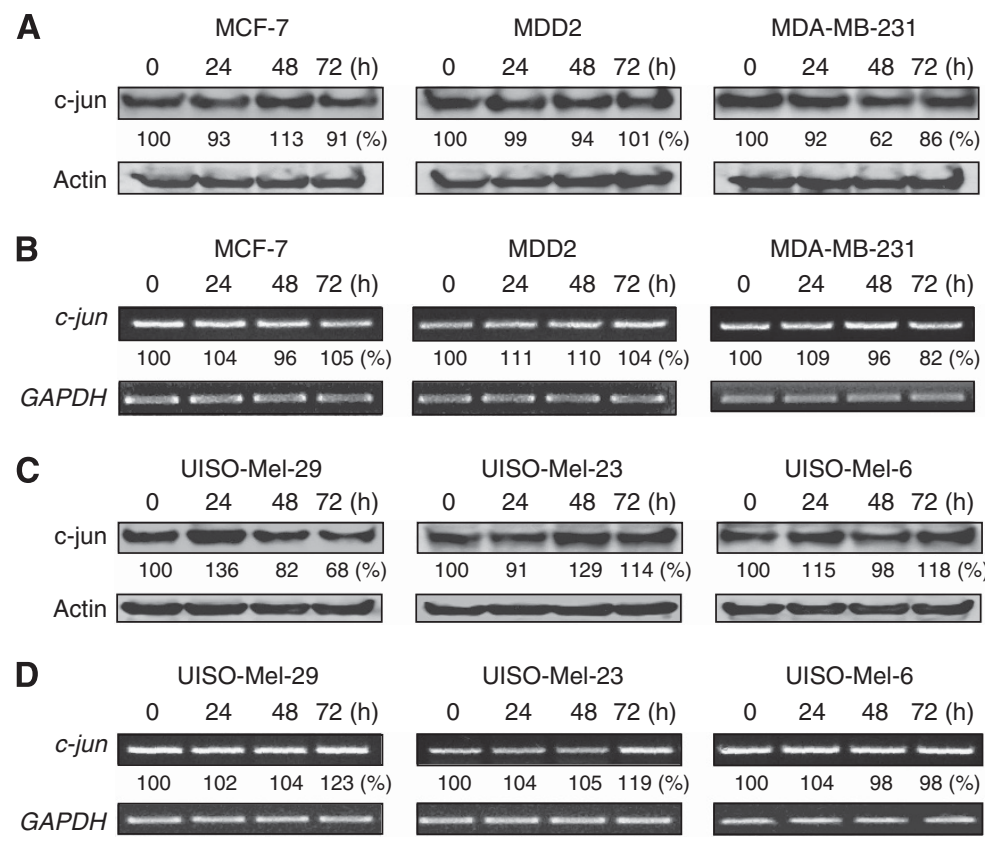

Figure 6. The effect of p28 on c-Jun. The protein level of c-Jun was determined in MCF-7, MDD2, MDA-MB-231 and MCF-10A cells (A), and Mel-29, Mel-23 and Mel-6 (C) treated with p28 at $50 \mu$ moll ${ }^{-1}$ for 24-72 h. The transcription level of c-Jun was determined by RT-PCR in breast cell lines (B) and melanoma cells (D). The numbers indicated below each band represent the relative to control (control expressed as $100 \%)$.

p28 significantly increased the level and transcription of HDM2 in $553^{\text {wt }}$ MCF-7 cells over $24-72 \mathrm{~h}$, while p53 levels remained elevated (Figure 4). The increase in HDM2 was minimal and delayed $(72 \mathrm{~h})$ in p53 ${ }^{\text {mut }}$ MDA-MB-231 cells. p28 had essentially no effect on HDM2 levels or transcription in $\mathrm{p} 53^{\mathrm{wt}} \mathrm{Mel}-29$, and induced only a delayed increase in HDM2 protein and RNA levels in p53 ${ }^{\mathrm{mut}}$ Mel-23 cells in spite of a sustained increase in p53 levels in both cell lines.

COP1 is overexpressed in breast and ovarian cancers (Dornan et al, 2004b), promotes p53 degradation via the proteasome pathway independently of HDM2 or Pirh2 (Dornan et al, 2004b) and is able to ubiquitinate itself (Bianchi et al, 2003; Dornan et al, 2006). We confirm that COP1 binds to aa $92-160$ and aa $318-393$ of p53 (Li et al, 2009). We show that p28 binds to specific motifs within the COP1-binding regions of the p53DBD, blocking COP1 binding and the subsequent ubiquitination and proteasomal degradation of p53. These motifs are distinct (Figure 1D) from those binding HDM2. The significant reduction in COP1 levels in breast cancer and melanoma cells (Figures 4 and 5) is not accompanied by an increase in the transcription of COP1 message, indicating the loss in COP1 is through autodegradation (Dornan et al, 2006). The p28-induced reduction in COP1 levels was also not accompanied by a significant or sustained increase in the transcription in c-Jun levels (Migliorini et al, 2011) that would be expected if a decrease in COP1 levels led to upregulation of c-Jun or altered its ubiquitination. Similarly, overexpression of COP1 does not result in a decrease in steady-state levels of c-Jun nor reduce c-Jun half-life (Bianchi et al, 2003).

The slight, transient increases and decreases in c-Jun levels were also unrelated to alterations in the expression of p53 or in c-Jun transcription (Figure 6) (Migliorini et al, 2011), and may result from as yet unknown modulating effects on the steady-state condition of c-Jun in individual cell lines as a result of exposure to p28. The sustained decrease in COP1 levels induced by p28 did not result in a c-Jun-dependent increase in cell proliferation (Figure 3) (Migliorini et al, 2011), again suggesting that a pharmacologically induced reduction in COP1 levels does not result in a c-Junmediated increase in tumour cell proliferation in either $\mathrm{p} 53^{\mathrm{wt}}$ or p53 ${ }^{\text {mut }}$ cancers (Migliorini et al, 2011).
On the basis of our findings, we propose a model for the stabilisation of $\mathrm{p} 53$ by $\mathrm{p} 28$ that results in a reduction in tumour growth through regulation of cell cycle-related genes. p28 binds to the $\mathrm{L}_{1}$ loop (aa 112-124) and additional motifs within the COP1-binding regions of the p53DBD (Figure 1D), subsequently inhibiting COP1-mediated p53 proteasomal degradation and stabilising p53. Increased levels of p53 upregulate the downstream molecules p21 (Figures 4A and 5A) and p27 (Yamada et al, 2009) in $\mathrm{p} 53^{\mathrm{wt}}$ and, at least some, p $53^{\mathrm{mut}}$ cancer cells, downregulating FoxM1, and leading to inhibition of cell cycle at $\mathrm{G}_{2}-\mathrm{M}$.

Currently, small molecules designed to inhibit HDM2-mediated ubiquitination are apparently only being tested in patients with $\mathrm{p} 53^{\mathrm{wt}}$ tumours (Kojima et al, 2010). Unlike these small molecules, p28 preferentially enters wide variety of cancer cells (Taylor et al, 2009) and enhances the cellular level of $\mathrm{p} 53^{\mathrm{wt}, \mathrm{mut}}$ by inhibiting the binding of COP1 independent of the HDM2 pathway. As such, p28 is a prototype molecule that exhibits efficacy in patients with advanced (Stage IV) p53 $3^{\mathrm{wt}, \mathrm{mut}}$ solid tumours (Warso et al, 2013).

\section{ACKNOWLEDGEMENTS}

We thank Scott Kennedy for editorial assistance. We thank CDG Therapeutics Inc. for the p28 used in these studies. Financial support was received from the Schenk Chair in Surgical Oncology, the Illinois Health Improvement Association and the NCI-DCT RAID programme. SS, ARB and SC thank the Italian Association for Cancer Research (AIRC No IG 10412) for supporting their research.

\section{CONFLICT OF INTEREST}

All terms of the research agreement between CDG Therapeutics, Inc., and UIC are managed by UIC in accordance with its conflict of interest management policies. 


\section{REFERENCES}

Apiyo D, Wittung-Stafshede P (2005) Unique complex between bacterial azurin and tumor-suppressor protein p53. Biochem Biophys Res Commun 332(4): 965-968.

Bektas N, Haaf A, Veeck J, Wild PJ, Luscher-Firzlaff J, Hartmann A, Knuchel R, Dahl E (2008) Tight correlation between expression of the Forkhead transcription factor FOXM1 and HER2 in human breast cancer. BMC Cancer 8: 42.

Belmont LD, Mitchison TJ (1996) Identification of a protein that interacts with tubulin dimers and increases the catastrophe rate of microtubules. Cell 84(4): 623-631.

Bianchi E, Denti S, Catena R, Rossetti G, Polo S, Gasparian S, Putignano S, Rogge L, Pardi R (2003) Characterization of human constitutive photomorphogenesis protein 1 , a RING finger ubiquitin ligase that interacts with Jun transcription factors and modulates their transcriptional activity. J Biol Chem 278(22): 19682-19690.

Bizzarri AR, Cannistraro S (2009) Atomic force spectroscopy in biological complex formation: strategies and perspectives. J Phys Chem B 113(52): 16449-16464.

Bizzarri AR, Di Agostino S, Andolfi L, Cannistraro S (2009) A combined atomic force microscopy imaging and docking study to investigate the complex between p53 DNA binding domain and Azurin. J Mol Recognit 22(6): 506-515.

Bizzarri AR, Santini S, Coppari E, Bucciantini M, Di Agostino S, Yamada T, Beattie CW, Cannistraro S (2011) Interaction of an anticancer peptide fragment of azurin with p53 and its isolated domains studied by atomic force spectroscopy. Int J Nanomed 6: 3011-3019.

Campomenosi P, Monti P, Aprile A, Abbondandolo A, Frebourg T, Gold B, Crook T, Inga A, Resnick MA, Iggo R, Fronza G (2001) p53 mutants can often transactivate promoters containing a p21 but not Bax or PIG3 responsive elements. Oncogene 20(27): 3573-3579.

Cheok CF, Verma CS, Baselga J, Lane DP (2011) Translating p53 into the clinic. Nat Rev Clin Oncol 8(1): 25-37.

De Grandis V, Bizzarri AR, Cannistraro S (2007) Docking study and free energy simulation of the complex between p53 DNA-binding domain and azurin. J Mol Recognit 20(4): 215-226.

Dornan D, Bheddah S, Newton K, Ince W, Frantz GD, Dowd P, Koeppen H, Dixit VM, French DM (2004a) COP1, the negative regulator of p53, is overexpressed in breast and ovarian adenocarcinomas. Cancer Res 64(20): 7226-7230.

Dornan D, Shimizu H, Mah A, Dudhela T, Eby M, O'Rourke K, Seshagiri S, Dixit VM (2006) ATM engages autodegradation of the E3 ubiquitin ligase COP1 after DNA damage. Science 313(5790): 1122-1126.

Dornan D, Wertz I, Shimizu H, Arnott D, Frantz GD, Dowd P, O’Rourke K, Koeppen H, Dixit VM (2004b) The ubiquitin ligase COP1 is a critical negative regulator of p53. Nature 429(6987): 86-92.

Duan W, Gao L, Wu X, Zhang Y, Otterson GA, Villalona-Calero MA (2006) Differential response between the p53 ubiquitin-protein ligases Pirh2 and MdM2 following DNA damage in human cancer cells. Exp Cell Res 312(17): 3370-3378.

Haupt Y, Maya R, Kazaz A, Oren M (1997) MDM2 promotes the rapid degradation of p53. Nature 387(6630): 296-299.

Hosaka M, Watanabe T, Sakai Y, Kato T, Takeuchi T (2005) Interaction between secretogranin III and carboxypeptidase E facilitates prohormone sorting within secretory granules. J Cell Sci 118(Part 20): 4785-4795.

Jia L, Gorman GS, Coward LU, Noker PE, McCormick D, Horn TL, Harder JB, Muzzio M, Prabhakar B, Ganesh B, Das Gupta TK, Beattie CW (2011) Preclinical pharmacokinetics, metabolism, and toxicity of azurin-p28 (NSC745104) a peptide inhibitor of p53 ubiquitination. Cancer Chemother Pharmacol 68(2): 513-524.

Kichina JV, Rauth S, Das Gupta TK, Gudkov AV (2003) Melanoma cells can tolerate high levels of transcriptionally active endogenous p53 but are sensitive to retrovirus-transduced p53. Oncogene 22(31): 4911-4917.

Kojima K, Burks JK, Arts J, Andreeff M (2010) The novel tryptamine derivative JNJ-26854165 induces wild-type p53- and E2F1-mediated apoptosis in acute myeloid and lymphoid leukemias. Mol Cancer Ther 9(9): 2545-2557.

Kozakov D, Hall DR, Beglov D, Brenke R, Comeau SR, Shen Y, Li K, Zheng J, Vakili P, Paschalidis I, Vajda S (2010) Achieving reliability and high accuracy in automated protein docking: ClusPro, PIPER, SDU, and stability analysis in CAPRI rounds 13-19. Proteins 78(15): 3124-3130.
Kubbutat MH, Jones SN, Vousden KH (1997) Regulation of p53 stability by Mdm2. Nature 387(6630): 299-303.

Laoukili J, Kooistra MR, Bras A, Kauw J, Kerkhoven RM, Morrison A, Clevers H, Medema RH (2005) FoxM1 is required for execution of the mitotic programme and chromosome stability. Nat Cell Biol 7(2): 126-136.

Lee MK, Teoh WW, Phang BH, Tong WM, Wang ZQ, Sabapathy K (2012) Cell-type, dose, and mutation-type specificity dictate mutant p53 functions in vivo. Cancer Cell 22(6): 751-764.

Lee YH, Andersen JB, Song HT, Judge AD, Seo D, Ishikawa T, Marquardt JU, Kitade M, Durkin ME, Raggi C, Woo HG, Conner EA, Avital I, Maclachlan I, Factor VM, Thorgeirsson SS (2010) Definition of ubiquitination modulator COP1 as a novel therapeutic target in human hepatocellular carcinoma. Cancer Res 70(21): 8264-8269.

Leng RP, Lin Y, Ma W, Wu H, Lemmers B, Chung S, Parant JM, Lozano G, Hakem R, Benchimol S (2003) Pirh2, a p53-induced ubiquitin-protein ligase, promotes p53 degradation. Cell 112(6): 779-791.

Li DQ, Divijendra Natha Reddy S, Pakala SB, Wu X, Zhang Y, Rayala SK, Kumar R (2009) MTA1 coregulator regulates p53 stability and function. J Biol Chem 284(50): 34545-34552.

Li YF, Wang DD, Zhao BW, Wang W, Huang CY, Chen YM, Zheng Y, Keshari RP, Xia JC, Zhou ZW (2012) High level of COP1 expression is associated with poor prognosis in primary gastric cancer. Int J Biol Sci 8(8): 1168-1177.

Ludwig RL, Bates S, Vousden KH (1996) Differential activation of target cellular promoters by p53 mutants with impaired apoptotic function. Mol Cell Biol 16(9): 4952-4960.

Mehta RR, Yamada T, Taylor BN, Christov K, King ML, Majumdar D, Lekmine F, Tiruppathi C, Shilkaitis A, Bratescu L, Green A, Beattie CW, Das Gupta TK (2011) A cell penetrating peptide derived from azurin inhibits angiogenesis and tumor growth by inhibiting phosphorylation of VEGFR-2, FAK and Akt. Angiogenesis 14(3): 355-369.

Mi Q, Lantvit D, Reyes-Lim E, Chai H, Zhao W, Lee IS, Peraza-Sanchez S, Ngassapa O, Kardono LB, Riswan S, Hollingshead MG, Mayo JG, Farnsworth NR, Cordell GA, Kinghorn AD, Pezzuto JM (2002) Evaluation of the potential cancer chemotherapeutic efficacy of natural product isolates employing in vivo hollow fiber tests. J Nat Prod 65(6): 842-850.

Michael D, Oren M (2003) The p53-Mdm2 module and the ubiquitin system. Semin Cancer Biol 13(1): 49-58.

Migliorini D, Bogaerts S, Defever D, Vyas R, Denecker G, Radaelli E, Zwolinska A, Depaepe V, Hochepied T, Skarnes WC, Marine JC (2011) Cop1 constitutively regulates c-Jun protein stability and functions as a tumor suppressor in mice. J Clin Invest 121(4): 1329-1343.

Olivier M, Eeles R, Hollstein M, Khan MA, Harris CC, Hainaut P (2002) The IARC TP53 database: new online mutation analysis and recommendations to users. Hum Mutat 19(6): 607-614.

Punj V, Bhattacharyya S, Saint-Dic D, Vasu C, Cunningham EA, Graves J, Yamada T, Constantinou AI, Christov K, White B, Li G, Majumdar D, Chakrabarty AM, Das Gupta TK (2004) Bacterial cupredoxin azurin as an inducer of apoptosis and regression in human breast cancer. Oncogene 23(13): 2367-2378.

Rajendra R, Malegaonkar D, Pungaliya P, Marshall H, Rasheed Z, Brownell J, Liu LF, Lutzker S, Saleem A, Rubin EH (2004) Topors functions as an E3 ubiquitin ligase with specific E2 enzymes and ubiquitinates p53. J Biol Chem 279(35): 36440-36444.

Reynolds C, Damerell D, Jones S (2009) ProtorP: a protein-protein interaction analysis server. Bioinformatics 25(3): 413-414.

Saleem A, Dutta J, Malegaonkar D, Rasheed F, Rasheed Z, Rajendra R, Marshall H, Luo M, Li H, Rubin EH (2004) The topoisomerase I- and p53binding protein topors is differentially expressed in normal and malignant human tissues and may function as a tumor suppressor. Oncogene 23(31): 5293-5300.

Shaulian E, Zauberman A, Ginsberg D, Oren M (1992) Identification of a minimal transforming domain of p53: negative dominance through abrogation of sequence-specific DNA binding. Mol Cell Biol 12(12): 5581-5592.

Sheng Y, Laister RC, Lemak A, Wu B, Tai E, Duan S, Lukin J, Sunnerhagen M, Srisailam S, Karra M, Benchimol S, Arrowsmith CH (2008) Molecular basis of Pirh2-mediated p53 ubiquitylation. Nat Struct Mol Biol 15(12): 1334-1342.

Taranta M, Bizzarri AR, Cannistraro S (2008) Probing the interaction between p53 and the bacterial protein azurin by single molecule force spectroscopy. J Mol Recognit 21(1): 63-70. 
Taylor BN, Mehta RR, Yamada T, Lekmine F, Christov K, Chakrabarty AM, Green A, Bratescu L, Shilkaitis A, Beattie CW, Das Gupta TK (2009) Noncationic peptides obtained from azurin preferentially enter cancer cells. Cancer Res 69(2): 537-546.

Tu C, Tan YH, Shaw G, Zhou Z, Bai Y, Luo R, Ji X (2008) Impact of lowfrequency hotspot mutation R282Q on the structure of p53 DNA-binding domain as revealed by crystallography at 1.54 angstroms resolution. Acta Crystallogr D Biol Crystallogr 64(Pt 5): 471-477.

Vitari AC, Leong KG, Newton K, Yee C, O’Rourke K, Liu J, Phu L, Vij R, Ferrando R, Couto SS, Mohan S, Pandita A, Hongo JA, Arnott D, Wertz IE, Gao WQ, French DM, Dixit VM (2011) COP1 is a tumour suppressor that causes degradation of ETS transcription factors. Nature 474(7351): 403-406.

Wang L, He G, Zhang P, Wang X, Jiang M, Yu L (2011) Interplay between MDM2, MDMX, Pirh2 and COP1: the negative regulators of p53. Mol Biol Rep 38(1): 229-236.

Warso MA, Richards JM, Mehta D, Christov K, Schaeffer C, Rae Bressler L, Yamada T, Majumdar D, Kennedy SA, Beattie CW, Das Gupta TK (2013) A first-in-class, first-in-human, phase I trial of p28, a non-HDM2mediated peptide inhibitor of p53 ubiquitination in patients with advanced solid tumours. Br J Cancer 108(5): 1061-1070.

Williams C, Norberg T, Ahmadian A, Ponten F, Bergh J, Inganas M, Lundeberg J, Uhlen M (1998) Assessment of sequence-based p53 gene analysis in human breast cancer: messenger RNA in comparison with genomic DNA targets. Clin Chem 44(3): 455-462.

Wiman KG (2006) Strategies for therapeutic targeting of the p53 pathway in cancer. Cell Death Differ 13(6): 921-926.

Yamada T, Fialho AM, Punj V, Bratescu L, Gupta TK, Chakrabarty AM (2005) Internalization of bacterial redox protein azurin in mammalian cells: entry domain and specificity. Cell Microbiol 7(10): 1418-1431.

Yamada T, Goto M, Punj V, Zaborina O, Chen ML, Kimbara K, Majumdar D, Cunningham E, Das Gupta TK, Chakrabarty AM (2002) Bacterial redox protein azurin, tumor suppressor protein $\mathrm{p} 53$, and regression of cancer. Proc Natl Acad Sci USA 99(22): 14098-14103.

Yamada T, Mehta RR, Lekmine F, Christov K, King ML, Majumdar D, Shilkaitis A, Green A, Bratescu L, Beattie CW, Das Gupta TK (2009) A peptide fragment of azurin induces a p53-mediated cell cycle arrest in human breast cancer cells. Mol Cancer Ther 8(10): 2947-2958.

Zupnick A, Prives C (2006) Mutational analysis of the p53 core domain L1 loop. J Biol Chem 281(29): 20464-20473.

This work is published under the standard license to publish agreement. After 12 months the work will become freely available and the license terms will switch to a Creative Commons AttributionNonCommercial-Share Alike 3.0 Unported License.

Supplementary Information accompanies this paper on British Journal of Cancer website (http://www.nature.com/bjc) 